\title{
$\mathrm{AFM}$ 기반 기계적 TNL 패터닝을 통한 PDMS 몰드제작
}

\author{
정윤준 ${ }^{a}$, 박정우 $^{b *}$
}

\section{Fabrication of PDMS Mold by AFM Based Mechanical TNL Patteming}

\author{
Y. J. Jung ${ }^{\mathrm{a}}$, J. W. Park ${ }^{\mathrm{b}^{*}}$ \\ ${ }^{a}$ Department of Advanced Parts and Materials Engineering, Chosun University, Republic of Korea \\ ${ }^{b}$ Department of Mechanical Design Engineering, Chosun University, Republic of Korea
}

\begin{tabular}{|c|c|c|c|}
\hline \multicolumn{4}{|c|}{ ARTICLE INFO } \\
\hline \multicolumn{4}{|c|}{ Article history: } \\
\hline Received & 24 & May & 2013 \\
\hline Revised & 8 & July & 2013 \\
\hline Accepted & 13 & July & 2013 \\
\hline
\end{tabular}

Keywords:

AFM (Atomic force microscope)

TNL (Tribo nanolithography)

PDMS (Polydimethylsiloxane)

Silicon wafer (100)

PCD (Polycrystallinediamond)

Micro/Nano

\begin{abstract}
This study demonstrates the process of fabricating patterns using tribonanolithography (TNL), with laboratory-made micro polycrystalline diamond (PCD) tools that are attached to an atomic force microscope (AFM). The various patterns are easily fabricated using mechanical scratching, under various normal loads, using thePCD tool on single crystal silicon, which is the master mold for replication in this study. Then, polydimethylsiloxane (PDMS) replica molds are fabricated using precise pattern transfer processes. The transferred patterns show high dimensional accuracy as compared with those of TNL-processed silicon micro molds. TNL can reduce the need forhigh cost and complicated apparatuses required for conventional lithography methods. TNL shows great potential in that it allows for the rapid fabrication of duplicated patterns through simple mechanical micromachining on brittle sample surfaces.
\end{abstract}

\section{1. 서 론}

최근 디스플레이, 정보저장 매체, 바이오 산업 등 다양한 분야에 서 마이크로/나노 단위의 고정밀, 고밀도 제품에 대한 수요가 급증 하고 있다. 이러한 초정밀 부품을 제작하기 위해 기존에는 포토리 소그래피, 전자빔, X-ray 리소그래피 등 다양한 기술들이 연구되어 왔다. 포토리소그래피 기술은 사진 현상 기술을 이용하는 방법으 로, 마스크에 빛을 조사하여 기판에 도포된 감광성 고분자를 패턴 의 형태로 변형시키고 에칭 공정을 거쳐 설계된 패턴을 제작하는 방식이다. 현재 포토 공정의 경우 빛의 회절 한계로 인해 $100 \mathrm{~nm}$ 단위의 선폭을 구현하고 있다 ${ }^{[1]}$. 그 외의 빛을 이용한 광 리소그래 피의 경우 복잡한 구조물 내에 수 많은 광학 렌즈를 사용하여 패턴

* Corresponding author. Tel.: +82-62-230-7277

$$
\text { Fax: }+82-62-230-7277
$$

E-mail address: jwoopark@chosun.ac.kr (Jeong Woo Park).
의 크기를 축소 인쇄하여 원하는 미세패턴을 간접적으로 웨이퍼 표면에 전사하는 기술이다. 이 공정의 경우 20-100 nm 크기의 패 턴을 제작 할 수 있지만 공정에 너무 많은 에너지와 시간이 요구되 고 장비의 가격이 매우 고가이며 기판 전체에 미세한 크기의 패턴 을 하나하나 형성해야 하는 방식이므로 효율적이지 못하다는 것을 알 수 있다. 이처럼 기존의 리소그래피 방식은 마이크로/나노 단위 패턴 제작 시 다양한 문제점이 대두되고 있어 이를 보완하기 위한 다양한 가공 방법에 대한 연구가 필요하다 ${ }^{[2]}$.

따라서 본 논문에서는 앞서 언급한 문제점들을 보완하기 위한 TNL (Tribo nanolithography) 방식의 미세 가공법에 대해 소개 하고자 한다. TNL은 고체표면을 원자 스케일로 관찰 하기 위하여 발명된 SPM (Scanning probe microsope)의 표면 측정원리를 가 
공을 위한 수단으로 적용하여 미세패턴을 제작하는 방법이다. $\mathrm{AFM}$ 기반의 $\mathrm{TNL}$ 은 측정용 캔틸레버에 초소형 $\mathrm{PCD}$ (Polycrystallinediamond) 공구를 부착한 후 공구에 하중을 가해 원하 는 형상의 패턴을 기판에 스크래치 가공을 하여 마이크로/나노 구 조물을 제작하는 기계적 방식의 리소그래피로써 기존의 마스크를 이용하여 패턴을 전사하고 이후 PR (Photo resist)제거 후 식각 공정이 요구되는 복잡한 과정과 높은 비용을 절감할 수 있는 리소 그래피이다 ${ }^{[3]}$. 본 실험은 초소형 $\mathrm{PCD}$ 공구 기반의 미세 패터닝 후 PDMS (Polydimethylsiloxane)를 이용하여 패턴을 복제하고 대량생산에 적합한 NIL (Nanoimprintlithography) 공정의 스탬 프로 활용하고자 한다 ${ }^{[4]}$.

\section{2. $\mathbf{A F M}$ 기반 $\mathrm{TNL}$ 의 원리}

$\mathrm{AFM}$ 은 전류가 흐르는 도체의 표면 밖에 측정할 수 없는 STM 의 단점을 극복하기 위해 고안된 장치로써, 절연물의 미세한 탐침 을 절연물 표면에 원자의 크기까지 근접시키면 양자의 원자간에 힘이 작용하게 된다. 탐침을 캔틸레버의 끝에 설치해 놓고 캔틸레 버에 도전체의 작은 바늘을 달아 터널전류를 측정하거나 광연자의 반사광의 편향을 검출하여 원자간의 힘을 측정함으로 표면을 측정

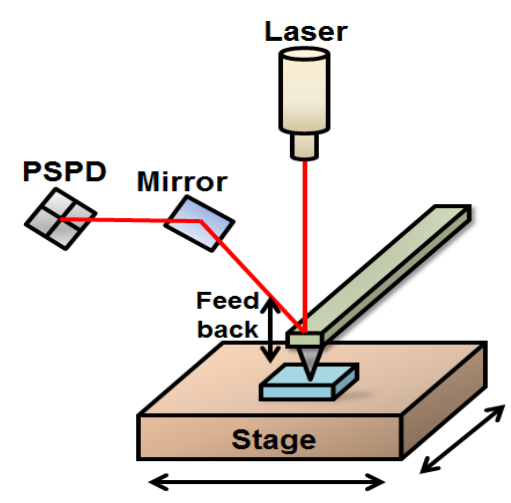

(a) Diagram of Atomic force microscope

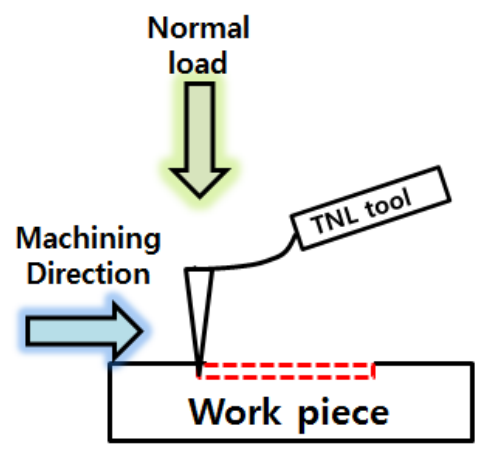

(b) Diagram of Tribo nanolithography

Fig. 1 Experimental setup for TNL based on AFM
하는 원리로 STM과 함께 급속하게 응용범위가 넓어지고 있다. 본 실험에서 제안하는 $\mathrm{TNL}$ 방법은 $\mathrm{AFM}$ 의 측정 원리를 응용한 가공 방법으로 피라미드 형상의 팁이 부착된 캔틸레버를 이용한다 ${ }^{[5]}$. 캔 틸레버와 팁이 소재표면을 가공하기에 충분한 강성을 가질 때 표면 을 스캐닝하는 방법으로 가공이 이루어진다. 이 때 캔틸레버에 가 해지는 하중과 팁의 형상, 제어 방식 등에 따라 패턴을 이루는 선의 폭과 깊이가 결정된다. Fig. 1의 (a)는 AFM의 일반적인 개념도를 나타낸 그림이고 (b)는 TNL의 원리를 나타내는 개념도이다. 레이 저가 캔틸러버에 조사된 후 반사되어 나오는 레이저를 분리된 PSPD (Position-sensitive photodiode) 로 캔틸레버가 편향되는 정도를 모니터링하여 탐침이 시료 표면에 일정한 편향이 유지되도 록 스캐너가 feed back을 실시한다. 이 때 항상 팁과 샘플간의 간 격이 Coulomb Force 대역에서 유지가 되도록 한담]

\section{3. 실험 방법}

마이크로/나노 단위의 미세패턴 가공을 위한 시편은 단결정 실리 콘 웨이퍼(100)을 사용하였고 웨이퍼 표면에 존재하는 먼지 및 유 기물과 자연적으로 발생한 산화층을 제거하기 위해 Piranha 클리 닝 공정을 거쳤다. 이 때 세척은 $\mathrm{H}_{2} \mathrm{SO}_{4}(98 \%)$ 와 $\mathrm{H}_{2} \mathrm{O}_{2}(30 \%)$ 의

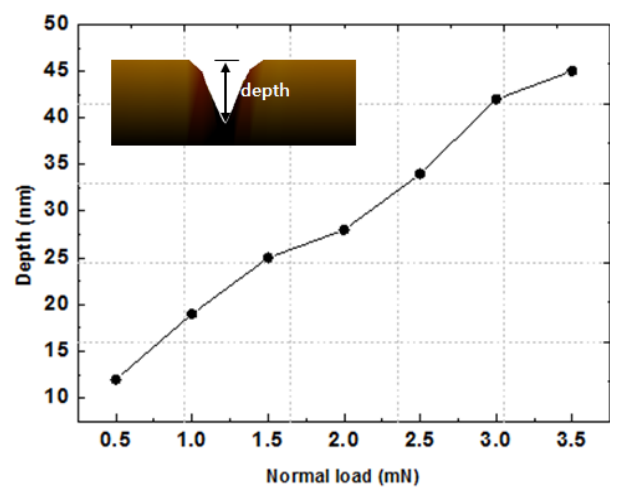

Fig. 2 Relationship between normal load and depth of pattems

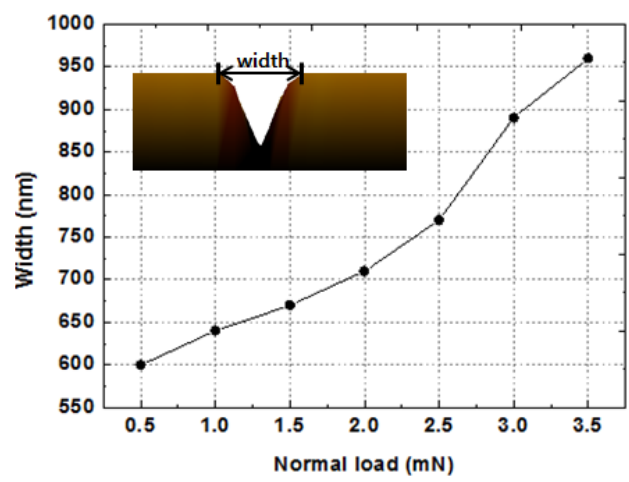

Fig. 3 Relationship between normal load and width of pattems 
혼합액 내에 2시간 동안 침지시켜 실시한 후 유기화합물을 제거하 기 위해 초음파세척기에서 초순수 세척(180초), 아세톤 세척(180 초), 다시 초순수 세척(180초) 순으로 수행하였다. 이후 흐르는 물 에 약 60 초간 세척한 후 표면의 수분을 제거하기 위해 데시케이터 내에서 1 시간의 자연건조 과정을 실시하였다. 세척과 건조가 완료 된 웨이퍼에 자체 제작한 초소형 $\mathrm{PCD}$ 공구가 장착된 $\mathrm{AFM}$ 을 이 용하여 $\mathrm{TNL}$ 을 수행하게 된다. 이 때 가공 조건으로는 Table 1과 같이 $20 \mu \mathrm{m} \times 20 \mu \mathrm{m}$ 의 가공 면적에 $10 \mu \mathrm{m} / \mathrm{s}$ 의 가공 속도로 스크래 치 가공을 실시하였으며 가변 조건으로는 $\mathrm{PCD}$ 공구의 하중을 각 각 $2.8 \mathrm{mN}, 2.3 \mathrm{mN}, 1.8 \mathrm{mN}, 1.3 \mathrm{mN}$ 으로 설정하였다. Fig. 2 는 공구의 하중에 따른 패턴의 가공 깊이에 대한 그래프이고 Fig. 3 은 하중과 선폭과의 관계에 대한 그래프이다. 하중이 증가 할 수 록 깊이와 폭이 증가하는 비례관계임을 알 수 있다. 하지만 본 실험 에서 사용한 $\mathrm{PCD}$ 공구의 경우 최대 허용 하중이 $3.5 \mathrm{mN}$ 이며 그 이상의 가공은 수행되지 않았다. 가공에 사용된 캔틸레버의 수직력 은 아래의 식 (1)에 의하여 구할 수 있으며 Fig. 4의 해석결과를 통해 휨강성에 대한 최대 허용 수직하중을 계산할 수 있다. 실제로 선단반경 $1 \mu \mathrm{m}$ 이하의 다이아몬드 팁을 부착하여 스크래치 실험을 할 경우, $2 \mathrm{mN}$ 이상의 수직하중에서는 상당한 표면가공이 이루어 지며 $4 \mathrm{mN}$ 영역에서는 크랙이 발생하기 시작한다 ${ }^{[3]}$.

$$
k_{b}=\frac{F}{x}=\frac{3 E I}{L^{3}}=\frac{E t^{3}\left(6 b^{2}+6 b b_{1}+b_{1}^{2}\right)}{12 L^{3}\left(2 b+b_{1}\right)}
$$

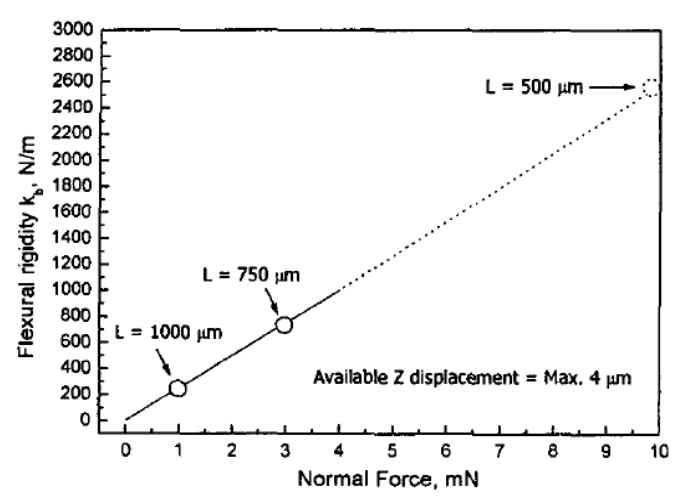

Fig. 4 Relationship between flexural rigidity and nomal force

Table 1 Experimental condition of mechanical process

\begin{tabular}{c|c|c}
\hline \hline $\begin{array}{c}\text { Machining } \\
\text { Area }\end{array}$ & $\begin{array}{c}\text { Machining } \\
\text { Speed }\end{array}$ & Normal Load $(\mathrm{mN})$ \\
\hline \multirow{4}{*}{$20 \mu \mathrm{m} \times 20 \mu \mathrm{m}$} & & 2.8 \\
\cline { 3 - 3 } & \multirow{3}{*}{$10 \mu \mathrm{m} / \mathrm{s}$} & 2.3 \\
\cline { 3 - 3 } & & 1.8 \\
\cline { 3 - 3 } & & 1.3 \\
\hline
\end{tabular}

따라서 TNL프로세스에서는 크랙이 발생하지 않는 하중 범위 내 에서 실행해야 하기 때문에 $\mathrm{PCD}$ 공구의 최대 수직 하중치는 $4 \mathrm{mN}$ 으로 설정하였다. 위의 기계적 가공을 통해 패턴을 제작한 후 고분 자 물질인 $\mathrm{PDMS}$ 와 경화제의 혼합액을 제조한다. 이 때 복제될 패턴의 정확도를 위해 혼합액내에 존재하는 미세 기포들을 탈포 장치에서 $1 \mathrm{MPa}$ 로 1 시간 동안 제거한다. 완성된 혼합액을 웨이퍼 표면에 붓고 적정 온도로 핫플레이트 위에서 베이킹 과정을 거친 다. 이후 상온에서 서서히 냉각 시킨 후 웨이퍼 표면으로부터 PDMS를 분리시키면 웨이퍼 표면의 원형 패턴이 좌우 대칭된 형 태의 복제 패턴을 얻을 수 있다.

본 실험에 사용된 장비는 초소형 $\mathrm{PCD}$ 공구는 피라미드 형상의 팁 $(100 \mu \mathrm{m} \times 100 \mu \mathrm{m})$ 을 실리콘 캔틸레버 (길이: $750 \mu \mathrm{m}$, 폭: 50 $\mu \mathrm{m}$, 두께: $45 \mu \mathrm{m}$, 강성: $790 \mathrm{~N} / \mathrm{m}$ )에 부착한 자체제작 공구와, PDMS 및 경화제는 SYLGARD 184를 사용하였다. 샘플로 사용 한 실리콘 웨이퍼는 (100) P-type이며 GLHPS-G 핫플레이트를 이용하여 베이킹 공정을 수행하였다. TNL 공정과 실리콘 웨이퍼 및 PDMS 몰드의 표면 측정 장비로는 Park system의 XE-100 $\mathrm{AFM}$ 을 이용하였다.

\section{4. 실험 결과}

\section{1 하중에 따른 TNL 가공 결과}

본 실험은 $\mathrm{AFM}$ 기반의 $\mathrm{TNL}$ 을 통한 미세 패턴 형성 및 $\mathrm{PDMS}$

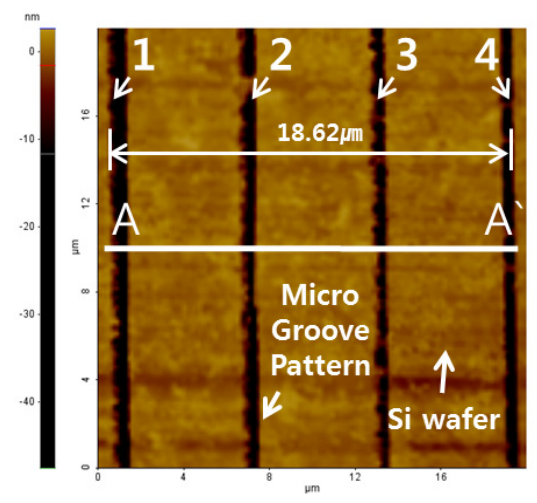

(a) AFM topographical image of micro-groove patterns

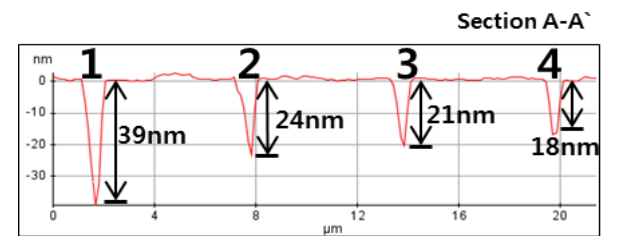

(b) Line profile of micro-groove patterns

Fig. 5 (a) AFM image and (b) line profile of micro-groove pattems on the silicon wafer 


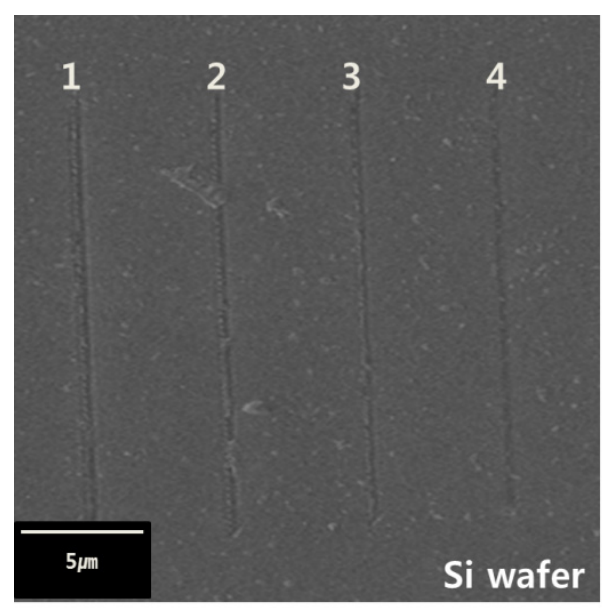

Fig. 6 SEM image of micro-groove pattems on the silicon wafer

몰드 제작에 관한 실험으로 Fig. 5는 초소형 $\mathrm{PCD}$ 공구의 하중에 따른 가공 결과를 $\mathrm{AFM}$ 이미지와 표면 프로파일을 나타낸 결과이 다. 그림을 보면 실리콘 웨이퍼

상에 선 폭이 서로 다른 4 개의 그루브 패턴이 있는 것을 확인 할 수 있다. 1, 2, 3, 4 은 공구의 하중의 차이에 따른 가공 깊이와 폭의 차이를 나타내고 있다. 초기에 설정한 하중인 $2.8 \mathrm{mN}, 2.3$ $\mathrm{mN}, 1.8 \mathrm{mN}, 1.3 \mathrm{mN}$ 에 따른 가공 결과인데 분석을 위해 임의의 구간 $\mathrm{A}-\mathrm{A}^{\prime}$ 를 정해 패턴의 정보를 획득하였다. 실리콘 웨이퍼 상에 제작된 패턴의 가로 전체의 길이는 $18.62 \mu \mathrm{m}$ 로 프로그램 입력값 $20 \mu \mathrm{m} \times 20 \mu \mathrm{m}$ 보다 조금 작은 수치였다. 1 번 선의 경우 가공 깊이 는 대략 $39 \mathrm{~nm}$ 이고 2번, 3번, 4번 순으로 각각 $24 \mathrm{~nm}, 21 \mathrm{~nm}$, $18 \mathrm{~nm}$ 였다.

앞서 그래프에서 확인 할 수 있듯 공구의 하중이 증가 하면 패턴 의 가공 깊이 역시 증가한다는 것을 알 수 있었다. Fig. 6 는 실리콘 웨이퍼 표면의 마이크로 그루브 패턴을 $\mathrm{SEM}$ 으로 촬영한 사진이 다. 왼쪽부터 차례대로 Fig. 4의 1, 2, 3, 4 번 선이 선명하게 나타 나있다.

\subsection{PDMS 복제몰드 제작 결과}

4.1 에서 제작된 실리콘 웨이퍼 표면의 미세패턴을 PDMS를 이 용하여 패턴 복제를 시도하였다. 정확한 패턴 복제를 위해 경화제 와 PDMS를 1:9의 비율로 혼합한 물질을 사용하였으며 베이킹 조 건은 $80^{\circ} \mathrm{C}$ 의 온도에서 5 분간 실시한 후 상온에서 30 분간 냉각 과 정을 실시하였다. Fig. 7은 PDMS 몰드에 복제된 패턴을 표면 마 찰을 고려해 $\mathrm{AFM}$ 의 비접촉 측정모드를 통해 측정한 결과와 힐록 패턴의 프로파일이다. 원형패턴과는 좌우 대칭된 형태의 패턴이므 로 왼쪽부터 차례대로 4, 3, 2, 1번 선이 복제된 4', 3', 2', 1'선임 을 알 수 있다. 결과 분석을 위해 임의의 구간 B-B'을 정해 힐록 패턴의 정보를 얻었다. $1^{\prime}$ 선은 $42 \mathrm{~nm}$ 의 힐록이 2', 3', 4'선은 각각

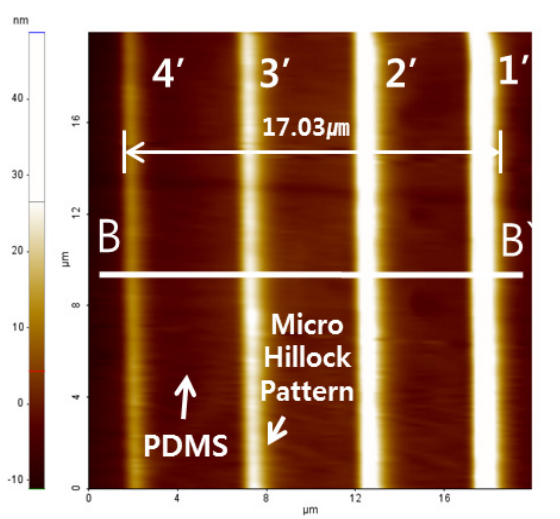

(a) AFM topographical image of micro hillock patterns

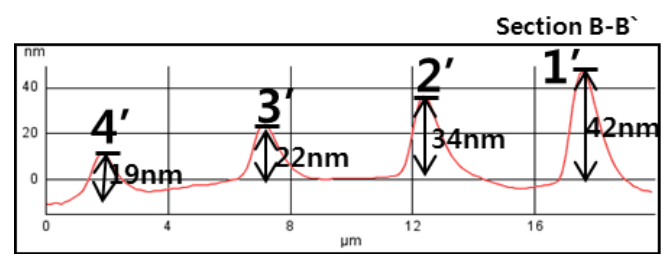

(b) Line profile of micro-hillock patterns

Fig. 7 (a) AFM image and (b) line profile of micro-hillock pattems on the silicon wafer

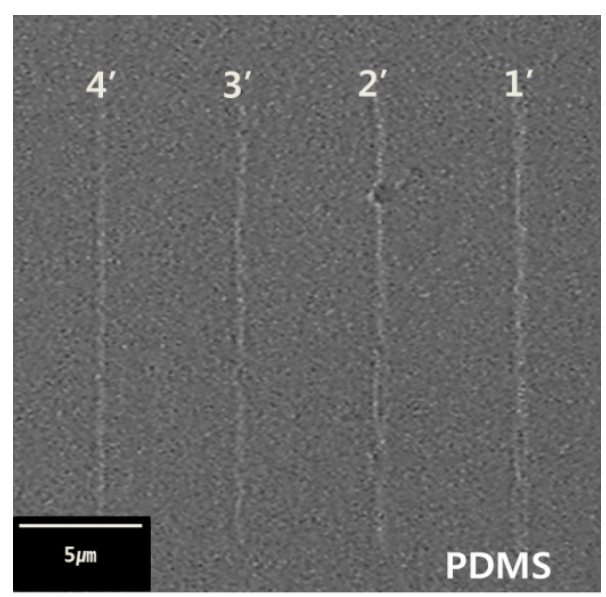

Fig. 8 SEM image of micro-hillock pattems on the PDMS mold

$34 \mathrm{~nm}, 22 \mathrm{~nm}, 19 \mathrm{~nm}$ 의 높이임을 확인 할 수 있다. Fig. 8은 복제된 패턴의 SEM 측정 이미지다. 왼쪽으로부터 4', 3', 2', 1'선 을 확인 할 수 있다.

\section{3 원형 패턴과 복제 패턴 분석}

서로 다른 하중이 가해진 4 개의 선 패턴을 임의의 구간 $\mathrm{A}-\mathrm{A}^{\prime}$ 와 복제된 몰드의 구간 B-B'로 설정하여 패턴분석을 실시하였다. 패 턴 전체의 가로 길이는 $18.62 \mu \mathrm{m}$ 에서 $17.03 \mu \mathrm{m}$ 로 줄어들며 $(100-9) \%$ 의 복제율을 보였다. 1 번 선의 깊이는 $39 \mathrm{~nm}$ 이고 1'선의 높이는 $42 \mathrm{~nm}$ 로 $+7.2 \%$ 의 복제율을 보였고 2 번선의 깊이는 24 

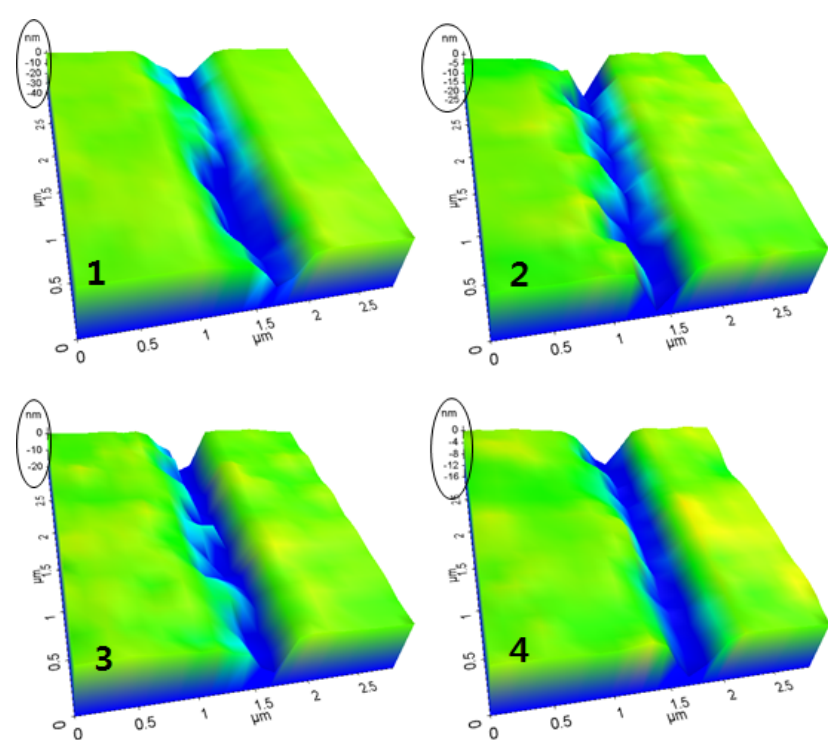

Fig. 9 AFM three-dimensional images of micro-groove pattems at various normal loads
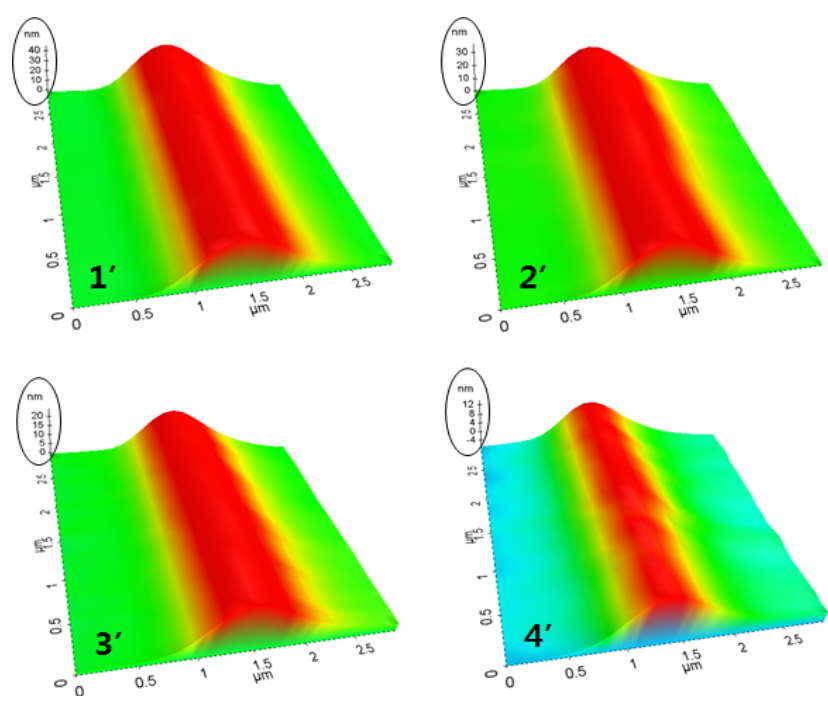

Fig. 10 AFM three dimentional image of replica PDMS mold

$\mathrm{nm}$ 에서 2'선 $34 \mathrm{~nm}$ 로 $+30 \%$ 의 큰 차이를 보이며 복제되었고 3 번 선의 경우 $21 \mathrm{~nm}$ 의 가공 깊이가 $3^{\prime}$ 선의 $22 \mathrm{~nm}$ 의 높이로 보이면서 $+4.6 \%$, 마지막 4 번선과 4 '선은 $18 \mathrm{~nm}$ 에서 $19 \mathrm{~nm}$ 로 $+5.3 \%$ 로 높은 복제율을 나타내었다. 4 개의 선 패턴과 전체 패턴의 크기에서 가공 전, 후의 패턴 복제율은 약 $88.8 \%$ 의 비율로 패턴 전사가 일어 났다. Fig. 9는 TNL 가공된 원형 패턴의 깊이와 선폭을 확인 할 수 있는 AFM 3차원 이미지이다. 공구의 하중과 선폭-깊이의 관계 를 쉽게 확인 할 수 있다. Fig. 10의 몰드는 Fig. 9 의 음각의 몰드로 $\mathrm{PDMS}$ 를 통해 복제된 패턴의 높이와 선폭을 볼 수 있다.

\section{5. 결 론}

본 연구는 초소형 $\mathrm{PCD}$ 공구 기반의 실리콘 웨이퍼 표면 패터닝 을 통한 PDMS 몰드 제작에 대한 실험 결과이다. 앞서 소개한 기 계적 방식의 TNL 가공을 이용하여 공구의 하중에 따른 선 형태의 패턴의 특성을 확인 하였다. 첫째 이 방법은 과정이 매우 복잡하고 시간이 오래 걸리는 기존의 리소그래피 방식에서 벗어난 기술로서 원하는 모양의 패턴을 간단한 공정과 짧은 시간에 제작 할 수 있었 다. 둘째 가격이 저렴하고 생산성이 뛰어나며 고정밀의 마이크로/ 나노 구조물 및 패턴 전사가 가능한 PDMS를 이용해 미세 패턴의 복제를 수행 할 때 약 $92 \%$ 에 이르는 복제율로 원형의 네가티브 형태의 패턴을 제작 할 수 있었다.

본 실험은 $\mathrm{TNL}$ 의 가공성과 $\mathrm{PDMS}$ 의 뛰어난 생산성을 활용한 복합 프로세스로서 최근 많은 연구가 이루어지고

있는 나노 임프린팅에 사용될 스탬프 제작의 차세대 기술이 될 수 있으며 IT, NT, BT 등 다양한 산업 분야에 적용이 가능한 복합 공정 기술이다 ${ }^{[7,8]}$.

\section{후 기}

본 연구는 2012 년도 정부(교육과학기술부)의 재원으로 한국연 구 재단의 지원(2012004235)을 받아 수행된 연구 과제입니다.

\section{References}

[1] Dai, H., Hafner, J. H., Rinzler, A. G., Colbert, D. T., Smalley, R. E., 1996, Nanotubes as Nanoprobes in Scanning Probe Microscopy, Nature, 384 147-150.

[2] Yavas, O., Ochiai, C., Takai, M., Hosono, A., Okuda S., 2000, Maskless Fabrication of Field-Emitter Array by Focused Ion and Electron Beam, Appl. Phys. Lett., 76 3319-3321.

[3] Park, J. W., Morita, N., Lee. D. W., 2010, Micro/Nano Surface Modification on Brittle Materials by Tribo Nanolithography Using PCD Tool, Nanotechnology, 10 4440-4447.

[4] Kawasegi, N., Takano, N., Oka, D., Morita, N., Yamada, S., Kanda, K., Takano, s., Obata, T. Asida, K., 2006, Nanomachining of Silicon Surface Using Atomic Force Microscope with Diamond Tip, J. Manuf. Sci. Eng., 128 723-729.

[5] Park, J. W., Lee, D. W., Kawasegi, N., Morita, N., 2004, 
Mechanical approach to nanomachining of silicon using oxide characteristics based on tribo nanolithography (TNL) in KOH Solution, J. Manuf. Sci. Eng.-Trans. ASME, 124 801-806.

[6] Kim, S. H., Park, J. W., 2012, AFM Based MechanoChemical Hybrid Surface Modification Process on PR-Coated Silicon Wafer, Adv. Sci. Lett, 13 193-198.
[7] Park, J. W., Lee, C. M., Choi, S. C., Kim, Y. W., Lee, D. W., 2008, Surface Patterning for Brittle Amorphous Material Using Nanoindenter-based Mehanochemical Nanofabrication, Nanotechnology, 19 85301-85305.

[8] Lee, J. M., Park, J. W., 2012, Inter Electrode Gap in Pulse Electrochemical Process for Local Oxidation of (100) Si Wafer, Advanced Science Letters, 13 62-65. 